\title{
Review Article \\ The Roles of Environmental Factors in Regulation of Oxidative Stress in Plant
}

\author{
Xiulan Xie, ${ }^{1}$ Zhouqing He, ${ }^{1}$ Nifan Chen, ${ }^{1}$ Zizhong Tang, ${ }^{1}$ Qiang Wang, ${ }^{2}$ and Yi Cai ${ }^{1}{ }^{1}$ \\ ${ }^{1}$ School of Life Sciences, Sichuan Agricultural University, Ya'an 625014, China \\ ${ }^{2}$ Institute of Ecological Agriculture, Sichuan Agricultural University, Chengdu 611130, China
}

Correspondence should be addressed to Yi Cai; yicai@sicau.edu.cn

Received 26 February 2019; Accepted 16 April 2019; Published 8 May 2019

Guest Editor: Hengjia Ni

Copyright (C) 2019 Xiulan Xie et al. This is an open access article distributed under the Creative Commons Attribution License, which permits unrestricted use, distribution, and reproduction in any medium, provided the original work is properly cited.

Exposure to a variety of environmental factors such as salinity, drought, metal toxicity, extreme temperature, air pollutants, ultraviolet-B (UV-B) radiation, pesticides, and pathogen infection leads to subject oxidative stress in plants, which in turn affects multiple biological processes via reactive oxygen species (ROS) generation. ROS include hydroxyl radicals, singlet oxygen, and hydrogen peroxide in the plant cells and activates signaling pathways leading to some changes of physiological, biochemical, and molecular mechanisms in cellular metabolism. Excessive ROS, however, cause oxidative stress, a state of imbalance between the production of ROS and the neutralization of free radicals by antioxidants, resulting in damage of cellular components including lipids, nucleic acids, metabolites, and proteins, which finally leads to the death of cells in plants. Thus, maintaining a physiological level of ROS is crucial for aerobic organisms, which relies on the combined operation of enzymatic and nonenzymatic antioxidants. In order to improve plants' tolerance towards the harsh environment, it is vital to reinforce the comprehension of oxidative stress and antioxidant systems. In this review, recent findings on the metabolism of ROS as well as the antioxidative defense machinery are briefly updated. The latest findings on differential regulation of antioxidants at multiple levels under adverse environment are also discussed here.

\section{Introduction}

The environment consists of a set of relationships between livings and nonliving things and is perfectly balanced by various natural processes. Each species influences its environment and, in turn, gets influenced by it. In general, numerous environmental factors including salinity, drought, extreme temperature, metal toxicity, air pollutants, ultraviolet light [1], and high doses of pesticides as well as pathogen infection can lead to subject oxidative stress in plants [2-6]. The oxidative stress is caused either by the direct effects of environmental stress or by indirect reactive oxygen species (ROS) generation and accumulation, which damage a cell before elimination. In order to evade stressors, animals are able to move and escape. Plants as sessile organisms, however, have developed complex strategies to release stressors. The plant cells will be in a state of "oxidative stress" if the ROS quantity is more than the inside defense mechanisms. It then exhibits growth retardation under oxidative stress, including flower and leaf abscission $[7,8]$, root gravitropism [9], seed germination [10], polar cell growth [11], lignin biosynthesis in cell wall [12], and cell senescence [13].

ROS include superoxide radical $\left(\mathrm{O}_{2}{ }^{--}\right)$, hydroxyl radical $\left(\mathrm{OH}^{*}\right)$, hydrogen peroxide $\left(\mathrm{H}_{2} \mathrm{O}_{2}\right)$, singlet oxygen $\left({ }^{1} \mathrm{O}_{2}\right)$, and so on $[14,15]$. They are regarded as natural byproducts of the aerobic way of life and are generated in different cellular compartments like chloroplasts, peroxisomes, mitochondria, and plasma membrane [16]. It is significant that the increase of ROS level is highly reactive and affects a large variety of cellular, physiological, and biochemical functions, such as the disruption of plasma membrane via carbohydrate deoxidation, lipid peroxidation, protein denaturation, and the destruction of DNA, RNA, enzymes, and pigments [17$20]$. All of those result in the loss of crop yield and quality [6, 21-27]. For example, in potatoes (Solanum tuberosum L.), overexpression of AtCYP21-4, a protein involved in oxidative stress tolerance, resulted in heavier tubers [28]. Similarly, in rice (Oryza sativa L.), OsCYP21-4 overexpressing transgenic plants exhibited higher biomass and productivity with 10$15 \%$ higher seed weight than in the WT [28]. Besides, in 
sweet oranges (Citrus sinensis L. Osbeck), overexpression of CitERF13 in citrus fruit peel resulted in rapid chlorophyll degradation and led to the accumulation of $\operatorname{ROS}[29,30]$. Moreover, in Arabidopsis (Arabidopsis thaliana), mutants of the singlet oxygen $\left({ }^{1} \mathrm{O}_{2}\right)$ overproducing flu and chlorinal (chl) have shown that ${ }^{1} \mathrm{O}_{2}$-induced changes in gene expression can lead to either PCD or acclimation [31]. In conclusion, all of those observations demonstrate that ROS have a significant impact on crop yield and quality.

In the past several decades, research on oxidative stress was mainly focused on Escherichia coli. In the past ten years, however, it has moved beyond animals (e.g., human) to plants, particularly model plants and crops (e.g., Arabidopsis thaliana, rice). It has substantially increased the understanding of the role and action of oxidative stress in general development-defense and environment-related responses [32-35]. Plants evolved their own antioxidant protection mechanism to maintain a dynamic balance of ROS, since the overcounteraction of ROS leads to the loss of an important intracellular signaling molecule [36].

This review primarily deals with the metabolism of ROS in plants and gives a brief introduction to the types, generation sites, and induced oxidative stresses of ROS. Then, we will focus on the antioxidative defense machinery in resisting the risk of overproduced ROS under disadvantageous environments and summarize recent researches on different environmental factors in regulating oxidative stress in plants.

\section{The Metabolism of ROS in Plants}

2.1. The Types of ROS. The most common ROS include $\mathrm{O}_{2}{ }^{\bullet-},{ }^{1} \mathrm{O}_{2}, \mathrm{H}_{2} \mathrm{O}_{2}$, and $\mathrm{OH}^{\bullet}$. The environment of molecular oxygen $\left(\mathrm{O}_{2}\right)$ is generally inactive due to its electron configuration [37]. But the unbalanced metabolism of $\mathrm{O}_{2}$ can lead to the production of ROS, which include both free radicals $\left(\mathrm{O}_{2}{ }^{\circ-}\right.$, superoxide radical; $\mathrm{OH}^{\bullet}$, hydroxyl radical; $\mathrm{HO}_{2}{ }^{\circ}$, perhydroxyl radical; and $\mathrm{RO}^{\circ}$, alkoxy radicals) and nonradical molecules $\left(\mathrm{H}_{2} \mathrm{O}_{2}\right.$, hydrogen peroxide; and ${ }^{1} \mathrm{O}_{2}$, singlet oxygen) $[5,15,38]$.

Among the various types of $\mathrm{ROS}, \mathrm{H}_{2} \mathrm{O}_{2}$ received most attention. It plays a vital role in the regulation of senescence process [39], stomatal behavior [40], cell wall crosslinking [41], regulation of the cell cycle [42], photosynthesis [43], stress acclimation [44], and antioxidative defense [45]. In addition, it is indicated that $\mathrm{H}_{2} \mathrm{O}_{2}$ can interact with other signal molecules such as abscisic acid (ABA), auxin, brassinosteroid (BR), and ethylene, which are important for plant development and senescence [46-48]. Both ABA and BR induce heat and paraquat tolerance via $\mathrm{H}_{2} \mathrm{O}_{2}$ produced by RBOH1 in tomato (Solanum lycopersicum L.) [49]. Moreover, ethylene mediates UV-B-induced stomatal closure through peroxidase-dependent $\mathrm{H}_{2} \mathrm{O}_{2}$ production in Vicia faba [50]. Besides, ethylene-induced stomatal closure is required for $\mathrm{H}_{2} \mathrm{O}_{2}$ synthesis, and both ethylene and $\mathrm{H}_{2} \mathrm{O}_{2}$ signaling mediate in guard cells in Arabidopsis [51]. The specificity of these responses allowing different signaling transduction pathways to act according to surrounding environmental triggers perceived and the physiological status of the plants is likely to be determined by spatial-temporal changes in $\mathrm{H}_{2} \mathrm{O}_{2}$ production and accumulation.

Several recent studies have demonstrated that $\mathrm{H}_{2} \mathrm{O}_{2}$ is involved in stress signal transduction pathways, which can activate multiple acclamatory responses that reinforce resistance to various biotic and abiotic stressors. Overexpression of pepper (Capsicum annuum) CaWRKY41 in Arabidopsis indicated that it impaired $\mathrm{Cd}$ tolerance, enhanced $\mathrm{Cd}$ levels through activating $\mathrm{Zn}$ transporters, and accelerated $\mathrm{H}_{2} \mathrm{O}_{2}$ accumulation. On the contrary, CaWRKY41 silenced via VIGS in pepper plants displayed increased Cd tolerance and reduced $\mathrm{H}_{2} \mathrm{O}_{2}$ levels [52]. Mutations of $\mathrm{Cu} / \mathrm{Zn}$ SOD1 (csd1), csd2, and $\operatorname{sod} x$ led to enhanced resistance to Magnaporthe oryzae and increased $\mathrm{H}_{2} \mathrm{O}_{2}$ accumulation in rice. Further studies revealed that they altered the expression of CSDs and other SOD family members, resulting in increased total SOD enzyme activity and leading to higher $\mathrm{H}_{2} \mathrm{O}_{2}$ production compared to WT [53]. These transgenic studies established the role of $\mathrm{H}_{2} \mathrm{O}_{2}$ in the formation of plant tolerance to different biotic and abiotic stresses.

2.2. The Production Sites of ROS. ROS are generated in both unstressed and stressed plant cells. Gradual reduction of $\mathrm{O}_{2}$ by high-energy exposure or electron-transfer reactions leads to the production of highly reactive ROS. In plants, the activation of ROS is energy dependent and requires an unavoidable leakage of electron from the electron transport activities of chloroplasts, peroxisomes, mitochondria, plasma membranes, endoplasmic reticulum (ER), apoplasts, and cell wall or as a byproduct of various metabolic pathways localized in different cellular compartments [48, 54-59].

Chloroplasts and peroxisomes are the main ROS generators in the presence of light, whilst the mitochondria are the chief sources of ROS production under dark conditions [1]. The chloroplast consists of a highly ordered system of thylakoids, which harbors the efficient light-capturing photosynthetic machinery. Photosystem (PS) I and PSII form the core of the light-harvesting systems in the thylakoids and are the primary sources of ROS generation [60, 61]. Near the reaction centers of PSII, $\mathrm{O}_{2}$ may produce ${ }^{1} \mathrm{O}_{2}$ when there is overexcitation of chlorophyll under stress conditions. Besides, $\mathrm{O}_{2}{ }^{--}$may also be formed at PSI via Mehler reaction [62] or at PSII during electron transfer to $\mathrm{O}_{2}$ through $\mathrm{Q}_{\mathrm{A}}$ and $\mathrm{Q}_{\mathrm{B}}$ [55]. Additionally, due to the activities of flavin oxidases, peroxisomes are the main sites of $\mathrm{H}_{2} \mathrm{O}_{2}$ generation $[58,63]$. In mitochondria, $\mathrm{O}_{2}{ }^{--}$and $\mathrm{H}_{2} \mathrm{O}_{2}$ may be generated by univalent reduction of $\mathrm{O}_{2}$ near electron transport chain in plant cell [57].

Apart from those organelles, there are cellular sites mediated in the generation of ROS. At plasma membrane that plays a vital role in sensing environmental conditions, localized NADPH-dependent oxidase transfers electrons from $\mathrm{NADPH}$ on cytoplasmic side to $\mathrm{O}_{2}$ producing $\mathrm{O}_{2}{ }^{--}$[59]. ER also mediates the generation of $\mathrm{O}_{2}{ }^{--}$by Cyt $\mathrm{P}_{450}$ [64]. During harsh environmental conditions, the apoplast is rendered for $\mathrm{H}_{2} \mathrm{O}_{2}$ production by stress signals combined with ABA [65]. As cell wall localized peroxidase(s), diamine/polyamine oxidases and oxalate oxidase produce $\mathrm{H}_{2} \mathrm{O}_{2}$ that may, in turn, 
be metabolized to $\mathrm{OH}^{*}$ by the activity of class III peroxidases $[66,67]$.

2.3. Oxidative Damage. When the level of ROS is low or moderate, they function as second messenger that mediates a series of reactions in plant cells, including stomatal closure, programmed cell death (PCD) [23], gravitropism [81], and acquisition of tolerance to both abiotic and biotic stresses [82]. However, in the past two decades, it has become more and more evident that all types of ROS at a high concentration are significantly harmful to organisms. Constant environmental stresses for plants will lead to the generation of superfluous ROS which cannot be completely disposed by the active oxygen scavenging system. Therefore, important physiological actions should be exerted, such as peroxidation of lipids, oxidation of nucleic acids, denaturation of proteins, inhibition of enzyme activity, and even activation of PCD pathway $[55,59]$.

The major targets of oxidative damage caused by ROS are lipids and proteins in plant cell. The oxidative decomposition of polyunsaturated lipids in plasma membrane, which is known as lipid peroxidation, occurs in every organism and is often considered as an indicator to determine the extent of lipid damage under severe conditions [83-85]. It is now well demonstrated that lipid peroxidation starts a reaction chain that can also create other reactive products such as ketones, aldehydes, and hydroxyl acids and can modify proteins, by oxidation of some amino acid residues $[86,87]$. The activity of the protein is altered due to modifications such as glutathionylation, carbonylation, nitrosylation, and disulfide bond formation [88].

\section{Antioxidative Defense System in Plants}

Environmental factors such as salinity, drought, chilling, metal toxicity, air pollutants, UV-B radiation, and high doses of pesticides as well as pathogen infection lead to enhanced production of ROS in plant cells $[89,90]$. Plenty of studies demonstrated the significance of intracellular antioxidant defense machinery against a variety of stresses [91-93]. This antioxidant defense machinery includes enzymatic and nonenzymatic components to scavenge ROS, and it operates at different subcellular compartments such as chloroplasts, peroxisomes, plasma membranes, and ER [59]. Enzymatic antioxidants contain enzymes such as superoxide dismutase (SOD), catalase [84], guaiacol peroxidase (GPX), ascorbate peroxidase (APX), guaiacol peroxidase (GPOX), monodehydroascorbate reductase (MDHAR), dehydroascorbate reductase (DHAR), glutathione reductase (GR), and glutathione Stransferases (GST) and nonenzymatic antioxidants which are ascorbic acid, glutathione, carotenoids, tocopherols, proline, glycine betaine, and flavonoids [94]. Additionally, NADPH oxidases and respiratory burst oxidase homologues (RBOHs) are also known to be major components of ROS production system in plants [95].

Initially, most of the studies on antioxidative defense system were focused on enzymatic characteristics due to the limitations of the experimental conditions. The enzymes of SOD, APX, CAT, etc. have been widely investigated in order to understand the antioxidative defense mechanisms in response to oxidative stress induced by various environmental factors. For instance, in alfalfa (Medicago sativa L.), after $\mathrm{NaCl}$ treatment, Xinmu No. 1 exhibited higher enzymatic activity of SOD, APX, and CAT in its shoots and roots than Northstar and, meanwhile, showed lower levels of $\mathrm{H}_{2} \mathrm{O}_{2}$ production and lipid peroxidation [96]. In another example, blue light illumination increased fruit color index, enhanced the activities of SOD, CAT, and APX, and maintained lower levels of $\mathrm{H}_{2} \mathrm{O}_{2}$ in strawberry (Fragaria vesca), which demonstrated that the treatment of blue light maintains fruit quality and increases nutritional value in strawberries due to the strengthening of both antioxidant systems and free radical elimination capabilities [97].

Subsequently, with the development of molecular cloning technology, researches on the functions of antioxidant genes generated many new insights into this area. The dynamic transcription activity of ROS-scavenging enzymatic genes has been widely characterized. In pear (Pyrus communis L.), the expression of $S O D, C A T$, and $A P X$ were significantly upregulated over 24, 48, 72, and $96 \mathrm{~h}$ after inoculation of Erwinia amylovora, comparing to the controls [98]. In cotton (Gossypium hirsutum), the expression patterns of 18 GhSOD genes were tested in different abiotic stresses, which indicated that they may play a very crucial role in ROS scavenging caused by various stresses through genome-wide characterization [99]. These expression patterns of SOD, $C A T$, and $A P X$ in pear and GhSOD suggest that they are associated with the antioxidative defense process. There have been a large number of similar studies on antioxidant genes expression in plants, focused mainly on the mRNA level, but further functional studies are limited.

In recent years, numbers of transgenic plants such as Arabidopsis, tomato, rice, tobacco, and maize have been developed with disposed expression of antioxidant enzymes that exhibited increased tolerance to salinity, extreme temperatures, and drought stress [100]. Jing et al. reported that overexpressing Kandelia candel KcCSD (a Cu/Zn SOD) in tobacco showed salinity tolerance in the aspect of lipid peroxidation, root growth, and survival rate and enhanced SOD and CAT activity compared to wild type (WT)[68]. Likewise, overexpression of Chinese cabbage (Brassica campestris) BcAPX2 and $B c A P X 3$ in Arabidopsis improved seed germination rate and showed amazing high temperature tolerance via efficient scavenging of cellular $\mathrm{H}_{2} \mathrm{O}_{2}$ [73]. In Arachis hypogaea, transgenic $A h C u Z n S O D$ in tobacco plants resulted in enhanced salinity and drought tolerance as indicated by better seed germination and higher chlorophyll content compared to WT [69]. Notably, overexpression of a single gene could increase plant tolerance to different stresses and many researchers paid close attention to transgenics with overexpression of SOD for enhancing stress tolerance [90].

As science advances, a growing amount of researches show that the stress tolerance can develop markedly by applying the simultaneous coexpression of genes involved in metabolic pathways. Xu et al. (2014) coexpressed $\mathrm{MeCu} /$ ZnSOD and MeAPX2 in cassava (Manihot esculenta Crantz) and tested the tolerance of transgenic plants against oxidative and chilling stresses. After exposure to $100 \mu \mathrm{M}$ methyl 
viologen and $0.5 \mathrm{M} \mathrm{H}_{2} \mathrm{O}_{2}$, the result exhibited a lower level of chlorophyll degreening, lipid peroxidation, and $\mathrm{H}_{2} \mathrm{O}_{2}$ accumulation along with a higher level of activities of SOD and APX in transgenic plants than the WT [75]. Similarly, coexpression of Brassica rapa BrMDHAR and $B r D H A R$ genes via hybridization conferred tolerance to freezing [101]; cotransformation of $c y t S O D$ and $c y t A P X$ led to salinity tolerance in transgenic plums [102]; coexpression of PaSOD and RaAPX genes from Potentilla atrosanguinea and Rheum austral, respectively, in transgenic Arabidopsis showed increased salt tolerance through regulating lignin deposition [70].

Genes encoding enzymes required for antioxidative defense have been widely studied in several types of plants. However, research on the transcriptional regulation of antioxidant enzymes remains limited and mainly focuses on the oxidative stress-related transcription factors including AP2/ERF, NAC, MYB, and bHLH family [15, 103-105]. For example, overexpression of the buckwheat (Fagopyrum tataricum) FtbHLH3 in Arabidopsis resulted in enhanced drought tolerance, which was attributed to not only the lower level of $\mathrm{H}_{2} \mathrm{O}_{2}$ but also the higher activities of SOD and CAT as well as the higher photosynthetic efficiency in transgenic lines compared to WT [106]. Overexpressing of rice miR529a led to enhanced plant resistance to high level of $\mathrm{H}_{2} \mathrm{O}_{2}$, which manifested as improved seed germination rate and increased SOD and POD activities, as well as reduced leaf rolling rate and chlorophyll content [107]. However, the underlying regulatory mechanisms specific to antioxidant enzymes are still not fully characterized and should be further explored.

\section{The Impact of Environmental Factors on Plant Oxidative Stress}

4.1. Salinity. Soil salinity is a major issue that limits the productivity and quality of the agricultural crops in many arid and semiarid regions of the world. Hypersaline conditions impact the stressed crops at multiple aspects such as oxidative stress, genotoxicity, ionic imbalance and toxicity, nutrition deficiency, and osmotic stress, resulting in subhealthy status of the plants [108]. As a consequence, plant cells decrease photosynthetic electron transport and generate excessive ROS. To counteract the deleterious effects mentioned above, plants have developed various strategies, including salt compartmentalization and exclusion [109].

In plants, all enzymatic scavengers operate together to conquer salt stress for better growth and development. In maize seedlings organs including roots, mature leaves, and young leaves, the activities of CAT and DHAR increased in all organs of salt-treated plants, while SOD, APX, GST, and GR increased specifically in the roots after $\mathrm{NaCl}$ treatment [110]. Two local wheat salt-tolerant cultivars, BARI Gom 27 and 28, displayed reduced accumulations of $\mathrm{H}_{2} \mathrm{O}_{2}$ and higher activities of CAT, peroxidase, and APX than saltsensitive cultivars in virtue of reduced oxidative damage [111]. In the above reports, higher expression level of enzymatic antioxidants induced by salt treatment suggests an efficient way to decrease saline toxicities. However, some studies also indicated that differential expression behavior of these enzyme genes, the salinity extent, and the exposure time as well as the plant developmental stage will make the expression levels different $[53,71,72]$.

Due to the significance of antioxidant enzymes, genetic engineering with altered antioxidant entities through overexpression of their pathway genes has been conducted to improve salt tolerance in various crops [72]. Zhou et al. (2018) demonstrated that Tyr-210 is a major phosphorylation site in CatC and is activated by STRK1 (receptor-like cytoplasmic kinase). Moreover, phosphorylating and activating CatC by overexpressing STRK1 regulated $\mathrm{H}_{2} \mathrm{O}_{2}$ homeostasis and indeed improved salt and oxidative tolerance. Importantly, overexpression of STRK1 in rice enhanced rice seedling growth status; meanwhile, the loss of grain yield under salt stress was significantly limited [112]. Guan et al. (2015) found that the expression of PutAPX was upregulated with extended exposure to $\mathrm{NaHCO}_{3}, \mathrm{NaCl}, \mathrm{H}_{2} \mathrm{O}_{2}$, and PEG6000 treatment in Puccinellia tenuiflora. Furthermore, when grown with 150 or $175 \mathrm{mM} \mathrm{NaCl}$, transgenic Arabidopsis plants overexpressing PutAPX displayed increased tolerance of saline toxicity and decreased level of lipid peroxidation [71].

4.2. Drought. Drought is an important environmental stress for plant growth that ultimately causes the reduction in crops yield in a global warming world, especially for commercial crops including rice, wheat, and maize [113]. Nevertheless, plants have evolved multiple strategies to minimize the damage during drought conditions [108]. It is demonstrated that the key process in plant physiological response to drought is the production of ROS, which causes progressive oxidative damage, stunted growth, and eventual cell death when ROS level reaches a certain threshold [89].

Several researches indicated that sustainable tolerance to drought stress could be achieved by increasing the expression/activity of ROS scavenging-related genes/enzymes [96]. For example, overexpression (OE) of OsLG3 (a ERF family transcription factor) increased rice drought tolerance by modulating ROS homeostasis through upregulation in the OE lines and downregulation in the RNAi lines of the expression of 10 ROS scavenging-related genes ( $A P X 1, A P X 2, A P X 4$, APX6, APX8, CATB, POD1, POD2, SODcc1, and FeSOD) [114]. Moreover, Xu et al. (2016) reported that the increasing cytokinin production through overexpression of isopentenyl transferase (ipt) alleviated drought damage and promoted root growth in Agrostis stolonifera. Further enzymatic assays and transcript abundance analysis showed that CAT, SOD, POD, and DHAR were much higher in roots of a transgenic line overexpressing ipt under drought stress [74]. In another example, Arabidopsis ZAT18 (a C2H2 zinc finger protein) OE plants exhibited less leaf water loss, lower content of $\mathrm{H}_{2} \mathrm{O}_{2}$, higher leaf water content, and higher activities of POD and CAT after drought treatment when compared with the WT [115].

The significant roles of oxidant enzymes in ROS scavenging also have been suggested by studies with transgenic plants. Wang et al. (2005) demonstrated that overexpression of pea (Pisum sativum) MnSOD in rice showed reduced electrolyte leakage compared to WT leaf slices after polyethylene glycol 6000 treatment, which could induce drought stress 
TABle 1: Antioxidant enzymatic defense mechanism in response to oxidative stress induced by various environmental factors.

\begin{tabular}{|c|c|c|c|c|}
\hline Environmental factors & Antioxidant enzymes & $\begin{array}{c}\text { Plant } \\
\text { species/source } \\
\text { crop }\end{array}$ & Recipient crop & References \\
\hline \multirow[t]{5}{*}{ salinity } & $\mathrm{Cu} / \mathrm{ZnSOD}, \mathrm{CAT}$ & Kandelia candel & tobacco & {$[68]$} \\
\hline & SOD & $\begin{array}{l}\text { Arachis } \\
\text { hypogaea }\end{array}$ & & [69] \\
\hline & PaSOD, RaAPX & $\begin{array}{c}\text { Potentilla } \\
\text { atrosanguinea } \\
\text { Rheum austral }\end{array}$ & Arabidopsis & {$[70]$} \\
\hline & PutAPX & $\begin{array}{c}\text { Puccinellia } \\
\text { tenuiflora }\end{array}$ & Arabidopsis & {$[71]$} \\
\hline & OsAPX & Oryza sativa & knockout & {$[72]$} \\
\hline \multirow[t]{2}{*}{ drought } & APX & $\begin{array}{l}\text { Solanum } \\
\text { melongena }\end{array}$ & Oryza sativa & {$[73]$} \\
\hline & & & & {$[74]$} \\
\hline \multirow[t]{2}{*}{ chilling } & SOD, APX & $\begin{array}{l}\text { Manihot } \\
\text { esculenta }\end{array}$ & & {$[75]$} \\
\hline & Glutaredoxins & $\begin{array}{c}\text { Arabidopsis } \\
\text { thaliana }\end{array}$ & Solanum lycopersicum & [76] \\
\hline \multirow[t]{2}{*}{ metal toxicity } & GR & Cannabis sativa & Cannabis sativa & {$[77]$} \\
\hline & GSH & synthetic & Oryza sativa & {$[78]$} \\
\hline UV-B radiations & APX, SOD, POD, CAT & $\begin{array}{c}\text { Pisum sativum } \\
\text { Cassia } \\
\text { auriculata }\end{array}$ & & [79] \\
\hline pathogens & peroxidase expression & Oryza sativa & mutation & {$[80]$} \\
\hline
\end{tabular}

[116]. Lu et al. (2010) reported that overexpressing $A P X$ and $\mathrm{Cu} / \mathrm{ZnSOD}$ in chloroplasts of sweet potato improved the capacity of drought tolerance and recovery in plants. It also exhibited enhanced photosynthetic activity when suffered drought stress, compared to WT [117].

4.3. Chilling. Chilling stress is a major restriction of crops growth, production, and distribution. Enhancing crop chilling tolerance is thus vital to crops yield increase. As chilling induces oxidative stress and results in lipid peroxidation, chlorophyll degradation, etc., chilling tolerance is thus mainly associated with antioxidant enzyme activities enhancement and corresponding $\mathrm{H}_{2} \mathrm{O}_{2}$ accumulation reduction (Table 1).

Glutaredoxins (GRXs), as common oxidoreductases, mainly utilize the reducing power of glutathione to break disulfide bonds of substrate proteins and maintain cellular redox homeostasis. It has been reported that the expression of AtGRXS17 in tomato conferred transgenic tomato chilling stress tolerance without any growth defects showing up. Compared with wild-type plants, tomato expressing AtGRXS17 exhibits lower ion leakage and increased maximal photochemical efficiency when challenged by cold [76]. Soluble sugar in those transgenic tomato plants also accumulates to a higher level.

$\mathrm{Xu}$ et al. (2014) coexpressed $\mathrm{MeCu} / \mathrm{ZnSOD}$ and MeAPX2 in cassava (Manihot esculenta Crantz) to enhance tolerance against oxidative attributed to chilling stresses. Specifically, higher levels of antioxidative enzymes activities and lower levels of chlorophyll degradation, lipid peroxidation, and $\mathrm{H}_{2} \mathrm{O}_{2}$ accumulation were detected in transgenic plants after exposure to $\mathrm{H}_{2} \mathrm{O}_{2}$ and methyl viologen, a ROS-generating reagent [75]. Similarly, BrMDHAR and BrDHAR coexpression in Brassica rapa via hybridization elevated the plant resistance to freezing [101].

4.4. Metal Toxicity. Since the industrial revolution, heavy metal environmental pollution has become so serious that an increasing number of scientists are engaged in relevant scientific research. Usually, the concentrations of heavy metals determine their negative impacts on plants and the environment [118]. Plants then exhibit their ability to avoid the detrimental impacts when the amount of heavy metals is controlled in a natural level [119]. There has already been evidence suggesting that excessive level of heavy metals impairs homeostasis and increases ROS production in the plant cells [120].

Due to the redox ability, heavy metals absorbed by plants are involved in several mechanisms that produce free radicals. As redox-active elements, iron $(\mathrm{Fe})$, copper $(\mathrm{Cu})$, chromium [121], etc., can participate in a redox-cycling reaction, resulting in the production of toxic hydroxyl radicals which seriously damage the living cells. Mannitol exhibits the ability to activate the antioxidant enzyme which might be helpful to alleviating pathological symptoms in wheat (Triticum aestivum L.) when challenged by $\mathrm{Cr}$ stress [122]. As for other metals without redox capacity, such as lead (Li), cadmium $(\mathrm{Cd})$, mercury $(\mathrm{Hg})$, zinc $(\mathrm{Zn})$, and nickel $(\mathrm{Ni})$, the primary route for their toxicity is to suppress the antioxidative system, which can be achieved by depleting glutathione and binding sulfhydryl groups of antioxidative enzymes including 
reductases, superoxide dismutase, and catalases [77]. They also meddle with photosynthetic process and consequently increase the superoxide and singlet oxygen generation within the cells [123]. As highlighted by several authors, the intensity of oxidative stress induced by heavy metals depends on species and varies across disparate genotypes, tissues, and/or developmental stages. In general, metal-susceptible plants display marked symptoms under oxidative stress, while metal-resistant plants display only mild or even no oxidative damages [119].

In addition to the antioxidant responses in plants, there have been a number of chemicals reported that may reduce the uptake of heavy metals and ameliorate the oxidative stress in plants. For example, the biochar derived from Citrus epicarp inhibited Abelmoschus esculentus (L.) Moench (okra) to absorb Cd from low Cd stress environment [124]. Decreasing $\mathrm{Cu}$ uptake and oxidative damage through applying exogenous SNP (Sodium Nitroprusside) and GSH (Glutathione) also alleviated copper toxicity in rice seedlings [78]. Besides, some fungus can provide plants with protections via mycorrhization [125].

4.5. UV-B Radiations. UV-B radiation ( $280-315 \mathrm{~nm})$ accompanies exposure to sunlight and is an inevitable abiotic factor for photosynthetic organisms. When plants are exposed to high level of UV-B radiation, a plethora of cell components, particularly the cellular macromolecules (DNA and protein), are interfered, and oxygen radicals are induced as a consequence. The effects of these radiations vary from the applied dose and sensitivity of living plant cells to the action of radiation type [126].

It has been known for many years that exposure of crop plants to physical radiations such as ionizing FN and nonionizing UV-B generates excessive free radicals which give rise to cytogenetic changes in plants [79]. A current study observed that almost all irradiation exposure doses of FN and UV-B exhibited special interference with meioticpollen mother cells and pollen grains leading to the genotoxic effect in Vicia faba L. [127]. The RUS1/RUS2 (Root UV-B Sensitive) complex, which works in UV-B-sensing pathway in root, is involved in seedling morphogenesis and development at early stages in Arabidopsis. In the absence of RUS1/RUS2 complex, the development of seedling is interfered with due to the dramatically increased signal generated from photoreceptors after the perception of UV-B [128].

4.6. Pathogens. Pathogen infection which causes plant diseases and epidemics has threatened plant growth, crop yield, and food security worldwide. Diverse and rapidly evolving characters make pathogen one of the most disastrous threats for plants. Different from vertebrates, sessile plants developed a conserved, unique yet sophisticated immune system to combat invading pathogens. Physical and chemical barriers deal with most of the microbes, while specific resistance responses termed host resistance handle the rest of them. When plants perceive PAMPs (Pathogen-associated Molecular Patterns), a multitude of immune responses within the cells will be triggered $[129,130]$.
ROS production is one of the responses mentioned above that bursts rapidly and transiently. It is mediated by NADPH oxidases located in plasma membrane, belonging to the respiratory burst oxidase homolog $(\mathrm{RBOH})$ family [131-133], as well as apoplastic peroxidases (PRXs). The mechanism of $\mathrm{RBOH}$ in stress response is well studied [134]. Kadota et al. (2014) has demonstrated that RBOHD phosphorylation mediated by BIK1 has biological significance for stomatal closure, ROS burst, and disease resistance against bacterial pathogens in PTI (PAMP-triggered immunity) [95]. Another example of ROS-related defense response is regulated by ACD11, whose binding partners are Arabidopsis BPA1 and its homologs. Those binding partners can be targeted by an effector, RxLR207, derived from Phytophthora capsici., and then ROS-mediated cell death, which is indispensable for virulence of $P$. capsici., is activated [135].

Another way to enhance plant disease resistance is to prevent $\mathrm{H}_{2} \mathrm{O}_{2}$ degradation catalyzed by peroxidases and to increase ROS burst to eliminate invading pathogens. A recent discovery found a natural mutation of the transcription factor that suppresses peroxidase expression and confers broadspectrum blast resistance in rice [80].

Nevertheless, the transcriptional regulation of ROSrelated genes in the apoplast remains largely controversial. For example, the expression of the apoplastic peroxidases coding genes PRX33 and PRX34 enhanced cytokininmediated stomatal immunity and plant resistance to bacteria [136]. It has also been reported that plants knocked down $P R X 33$ and PRX34 exhibited enhanced disease resistance to the necrotrophic fungus Alternaria brassicicola [137].

Although ROS burst and accumulation cause damage to plant cells, the generation of ROS is indispensable in plant immunity. Owing to the signaling and bactericidal functions of ROS, short-term oxidative stress is utilized by plant immune system as an effective way to defend against pathogens. The dual roles of ROS in signal transduction help plants detect pathogen invasion. Still, the production of ROS needs to be strictly regulated to control its function.

ROS and $\mathrm{Ca}{ }^{2+}$ waves contribute to rapid systemic signaling, which is crucial to plant adaptation to abiotic stresses [138]. Besides, plant resistance to pathogens can be attenuated or enhanced by abiotic stress factors [139]. ROS production bursts in a few minutes after immunogenic treatment; thus, this biological process can be detected to uncover the contribution of those plant components that are necessary in the burst of early immune responses [133].

\section{Conclusions}

Plants face a variety of pressure during their growth, especially environmental pressure including salinity, drought, extreme temperature, metal toxicity, UV-B radiation, pesticides, and pathogen infection. They adapt to those conditions with adjustments at molecular, biochemical, and physiological levels, especially via antioxidant systems. Although the general process of ROS formation as well as the antioxidative defense of plants (Figure 1) are understood, it is still unclear how plants detect stresses and prepare themselves for the incoming threats because of the extremely reactive nature and 


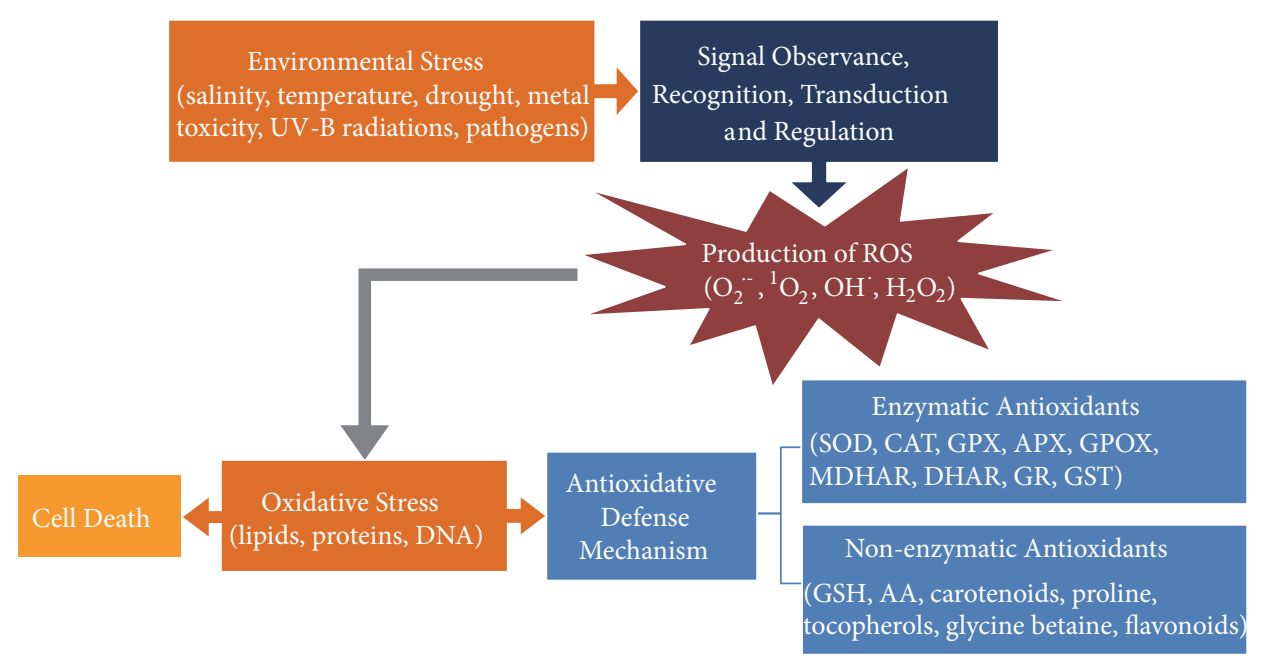

FIGURE 1: Environmental stress induced ROS generation, antioxidative defense, and cell death in plant.

short half-life of ROS. In recent studies, genetically modified plants with overexpressing functional genes have shown promising traits in combating oxidative stress. Moreover, to achieve high tolerance against various adverse environments, efforts should be made to generate transgenic plants by coexpressing multiple effective genes.

\section{Conflicts of Interest}

The authors declare that there are no conflicts of interest regarding the publication of this paper.

\section{Authors' Contributions}

Xiulan Xie and Zhouqing He contributed equally to this work.

\section{Acknowledgments}

This work was supported by the National Natural Science Foundation of China (31801839); the Henry Fok Foundation (151104); Ministry of Human Resources and Social Security, China; Sichuan Provincial Department of Science and Technology, China (2018HH0042, 2016JQ0009); Sichuan Provincial Department of Education, China (16TD0005, 15ZA0001).

\section{References}

[1] S. Choudhury, P. Panda, L. Sahoo, and S. K. Panda, "Reactive oxygen species signaling in plants under abiotic stress," Plant Signaling and Behavior, vol. 8, no. 4, Article ID e236811, 2013.

[2] J. H. L. Pacheco, M. A. Carballo, and M. E. Gonsebatt, "Antioxidants against environmental factor-induced oxidative stress," in Nutritional Antioxidant Therapies: Treatments and Perspectives, K. H. Al-Gubory, Ed., vol. 8, pp. 189-215, Springer, Cham, Switzerland, 2018.

[3] F. S. Farnese, P. E. Menezes-Silva, G. S. Gusman, and J. A. Oliveira, "When bad guys become good ones: the key role of reactive Oxygen species and Nitric Oxide in the plant responses to abiotic stress," Frontiers in Plant Science, vol. 7, p. 471, 2016.

[4] R. C. Foley, B. N. Kidd, J. K. Hane, J. P. Anderson, and K. B. Singh, "Reactive oxygen species play a role in the infection of the necrotrophic fungi, Rhizoctonia solani in wheat," PLOS ONE, vol. 11, no. 3, Article ID e0152548, 2016.

[5] M. A. Hossain, S. Bhattacharjee, S. Armin et al., "Hydrogen peroxide priming modulates abiotic oxidative stress tolerance: insights from ROS detoxification and scavenging," Frontiers in Plant Science, vol. 6, no. 420, 2015.

[6] M. Sabir, E. A. Waraich, K. R. Hakeem, M. Öztürk, H. R. Ahmad, and M. Shahid, "Chapter 4 -phytoremediation: mechanisms and adaptations," in Soil Remediation and Plants, K. R. Hakeem, M. Sabir, M. Öztürk, and A. R. Mermut, Eds., pp. 85105, Academic Press, San Diego, Calif, USA, 2015.

[7] P. Muñoz and S. Munné-Bosch, "Photo-oxidative stress during leaf, flower and fruit development," Plant Physiology, vol. 176, no. 2, pp. 1004-1014, 2018.

[8] S. Goldental-Cohen, C. Burstein, I. Biton et al., "Ethephon induced oxidative stress in the olive leaf abscission zone enables development of a selective abscission compound," BMC Plant Biology, vol. 17, no. 1, p. 87, 2017.

[9] S. Mugnai, C. Pandolfi, E. Masi et al., "Oxidative stress and NO signalling in the root apex as an early response to changes in gravity conditions," BioMed Research International, vol. 2014, Article ID 834134, 10 pages, 2014.

[10] Y. Shi, Y. Zhang, H. Yao, J. Wu, H. Sun, and H. Gong, "Silicon improves seed germination and alleviates oxidative stress of bud seedlings in tomato under water deficit stress," Plant Physiology and Biochemistry, vol. 78, pp. 27-36, 2014.

[11] S. Mangano, S. P. D. Juárez, and J. M. Estevez, "ROS regulation of polar growth in plant cells," Plant Physiology, vol. 171, no. 3, pp. 1593-1605, 2016.

[12] M. Chialva, A. Salvioli di Fossalunga, S. Daghino et al., "Native soils with their microbiotas elicit a state of alert in tomato plants," New Phytologist, vol. 220, no. 4, pp. 1296-1308, 2018.

[13] H. Bu, S. Wedel, M. Cavinato, and P. Jansen-Dürr, "MicroRNA regulation of oxidative stress-induced cellular senescence," Oxidative Medicine and Cellular Longevity, vol. 2017, Article ID 2398696, 12 pages, 2017. 
[14] D. K. Gupta, L. B. Pena, M. C. Romero-Puertas et al., "NADPH oxidases differentially regulate ROS metabolism and nutrient uptake under cadmium toxicity," Plant Cell \& Environment, vol. 40, no. 4, 2016.

[15] R. Kalia, S. Sareen, A. Nagpal et al., "ROS-induced transcription factors during oxidative stress in plants: a tabulated review," in Reactive Oxygen Species and Antioxidant Systems in Plants: Role and Regulation under Abiotic Stress, M. Khan and N. Khan, Eds., pp. 129-158, Springer, Singapore, 2017.

[16] K. Apel and H. Hirt, "Reactive oxygen species: metabolism, oxidative stress, and signal transduction," Annual Review of Plant Biology, vol. 55, pp. 373-399, 2004.

[17] S. Li, X. Sun, and X. Ma, "Effects of cyclic tensile strain on oxidative stress and the function of schwann cells," BioMed Research International, vol. 2018, Article ID 5746525, 6 pages, 2018.

[18] V. Van Ruyskensvelde, F. Van Breusegem, and K. Van Der Kelen, "Post-transcriptional regulation of the oxidative stress response in plants," Free Radical Biology \& Medicine, vol. 122, pp. 181-192, 2018.

[19] Y. Martínez, X. Li, G. Liu et al., "The role of methionine on metabolism, oxidative stress, and diseases," Amino Acids, vol. 49, no. 12, pp. 2091-2098, 2017.

[20] S. Bose, Y. Du, P. Takhistov, and B. Michniak-Kohn, "Formulation optimization and topical delivery of quercetin from solid lipid based nanosystems," International Journal of Pharmaceutics, vol. 441, no. 1-2, pp. 56-66, 2013.

[21] M. Sharma, S. Gupta, F. Deeba et al., "Effects of reactive oxygen species on crop productivity: an overview," in Reactive Oxygen Species in Plants, V. P. Singh, S. Singh, D. K. Tripathi, S. M. Prasad, and D. K. Chauhan, Eds., John Wiley \& Sons Ltd., 2017.

[22] S. Fulda, "Regulation of necroptosis signaling and cell death by reactive oxygen species," biological chemistry, vol. 397, no. 7, pp. 657-660, 2016.

[23] V. Petrov, J. Hille, B. Mueller-Roeber, and T. S. Gechev, "ROSmediated abiotic stress-induced programmed cell death in plants," Frontiers in Plant Science, vol. 6, article no. 69, 2015.

[24] M. Shahid, S. Khalid, G. Abbas et al., "Heavy metal stress and crop productivity," in Crop Production and Global Environmental Issues, K. Hakeem, Ed., pp. 1-25, Springer, Cham, Switzerland, 2015.

[25] M. L. Reshi, Y. C. Su, and J. R. Hong, "RNA viruses: ROSmediated cell death," International Journal of Cell Biology, vol. 2014, Article ID 467452, 16 pages, 2014.

[26] Y. Guo and S.-S. Gan, "Translational researches on leaf senescence for enhancing plant productivity and quality," Journal of Experimental Botany, vol. 65, no. 14, pp. 3901-3913, 2014.

[27] J. You and Z. Chan, "Ros regulation during abiotic stress responses in crop plants," Frontiers in Plant Science, vol. 6, p. 1092, 2015.

[28] H. J. Park, A. Lee, S. S. Lee et al., "Overexpression of golgi protein CYP21-4s improves crop productivity in potato and rice by increasing the abundance of mannosidic glycoproteins," Frontiers in Plant Science, vol. 8, p. 1250, 2017.

[29] X.-L. Xie, X.-J. Xia, S. Kuang et al., "A novel ethylene responsive factor CitERF13 plays a role in photosynthesis regulation," Journal of Plant Sciences, vol. 256, pp. 112-119, 2017.

[30] X. Yin, X. Xie, X. Xia et al., "Involvement of an ethylene response factor in chlorophyll degradation during citrus fruit degreening," The Plant Journal, vol. 86, no. 5, pp. 403-412, 2016.
[31] L. Shumbe, A. Chevalier, B. Legeret, L. Taconnat, F. Monnet, and M. Havaux, "Singlet oxygen-induced cell death in arabidopsis under high-light stress is controlled by OXI1 kinase," Plant Physiology, vol. 170, no. 3, pp. 1757-1771, 2016.

[32] A. C. B. A. Lopes, T. S. Peixe, A. E. Mesas et al., "Lead exposure and oxidative stress: a systematic review," Reviews of Environmental Contamination \& Toxicology, vol. 236, p. 193, 2016.

[33] A. M. Pisoschi and A. Pop, "The role of antioxidants in the chemistry of oxidative stress: a review," European Journal of Medicinal Chemistry, vol. 97, pp. 55-74, 2015.

[34] A. C. Maritim and R. A. Sanders, "Diabetes, oxidative stress, and antioxidants: a review," Journal of Biochemical \& Molecular Toxicology, vol. 17, no. 1, pp. 24-38, 2010.

[35] G. Guan and S. Lan, "Implications of antioxidant systems in inflammatory bowel disease," BioMed Research International, vol. 2018, Article ID 1290179, 7 pages, 2018.

[36] F. Afzal, R. Khurshid, M. Ashraf et al., "Chapter 13 - reactive oxygen species and antioxidants in response to pathogens and wounding," in Oxidative Damage to Plants, P. Ahmad, Ed., vol. 13, pp. 397-424, Academic Press, 2014.

[37] E. F. Elstner, "Metabolism of activated oxygen species," in The Biochemistry of Plants: A Comprehensive Treatise, D. D. Davies, Ed., vol. 8, pp. 253-315, Elsevier, 1987.

[38] A. Trchounian, M. Petrosyan, and N. Sahakyan, "Plant cell redox homeostasis and reactive oxygen species," in Redox State as a Central Regulator of Plant-Cell Stress Responses, D. Gupta, J. Palma, and F. Corpas, Eds., pp. 25-50, Springer, Cham, Switzerland, 2016.

[39] I. Jajic, T. Sarna, and K. Strzalka, "Senescence, stress, and reactive oxygen species," Plants, vol. 4, no. 3, pp. 393-411, 2015.

[40] O. Rodrigues, G. Reshetnyak, A. Grondin et al., "Aquaporins facilitate hydrogen peroxide entry into guard cells to mediate ABA- and pathogen-triggered stomatal closure," Proceedings of the National Acadamy of Sciences of the United States of America, vol. 114, no. 34, pp. 9200-9205, 2017.

[41] J. Li, R. Zhong, and E. T. Palva, "WRKY70 and its homolog WRKY54 negatively modulate the cell wall-associated defenses to necrotrophic pathogens in Arabidopsis," PLOS ONE, vol. 12, no. 8, Article ID e0183731, 2017.

[42] W. Pokora, A. Aksmann, A. Baścik-Remisiewicz et al., "Changes in nitric oxide/hydrogen peroxide content and cell cycle progression: study with synchronized cultures of green alga Chlamydomonas reinhardtii," Journal of Plant Physiology, vol. 208, pp. 84-93, 2017.

[43] M. Exposito-Rodriguez, P. P. Laissue, G. Yvon-Durocher, N. Smirnoff, and P. M. Mullineaux, "Photosynthesis-dependent $\mathrm{H} 2 \mathrm{O} 2$ transfer from chloroplasts to nuclei provides a high-light signalling mechanism," Nature Communications, vol. 8, no. 1, p. 49, 2017.

[44] X. Lv, H. Li, X. Chen et al., "The role of calcium-dependent protein kinase in hydrogen peroxide, nitric oxide and ABAdependent cold acclimation," Journal of Experimental Botany, vol. 69, no. 16, pp. 4127-4139, 2018.

[45] Y. Liu, L. Wang, H. Liu et al., “The antioxidative defense system is involved in the premature senescence in transgenic tobacco (Nicotiana tabacum NC89)," Biological Research, vol. 49, no. 1, p. 30, 2016.

[46] A. Krishnamurthy and B. Rathinasabapathi, "Oxidative stress tolerance in plants: novel interplay between auxin and reactive oxygen species signaling," Plant Signaling and Behavior, vol. 8, no. 10, Article ID e25761, 2013. 
[47] M. Alqurashi, L. Thomas, C. Gehring, and C. Marondedze, "A microsomal proteomics view of $\mathrm{H} 2 \mathrm{O} 2$ - and ABA-dependent responses," Proteomes, vol. 5, no. 3, p. 22, 2017.

[48] X.-J. Xia, Y.-H. Zhou, K. Shi, J. Zhou, C. H. Foyer, and J.-Q. Yu, "Interplay between reactive oxygen species and hormones in the control of plant development and stress tolerance," Journal of Experimental Botany, vol. 66, no. 10, pp. 2839-2856, 2015.

[49] J. Zhou, J. Wang, X. Li et al., "H2O2 mediates the crosstalk of brassinosteroid and abscisic acid in tomato responses to heat and oxidative stresses," Journal of Experimental Botany, vol. 65, no. 15, pp. 4371-4383, 2014.

[50] J. He, X. Yue, R. Wang, and Y. Zhang, "Ethylene mediates UV-Binduced stomatal closure via peroxidase-dependent hydrogen peroxide synthesis in Vicia faba L.," Journal of Experimental Botany, vol. 62, no. 8, pp. 2657-2666, 2011.

[51] X.-M. Ge, H.-L. Cai, L. Xue et al., "Heterotrimeric G protein mediates ethylene-induced stomatal closure via hydrogen peroxide synthesis in Arabidopsis," Plant Journal for Cell \& Molecular Biology, vol. 82, no. 1, pp. 138-150, 2015.

[52] F. Dang, J. Lin, Y. Chen et al., "A feedback loop between CaWRKY41 and $\mathrm{H} 2 \mathrm{O} 2$ coordinates the response to Ralstonia solanacearum and excess cadmium in pepper," Journal of Experimental Botany, vol. 70, no. 5, pp. 1581-1595, 2019.

[53] Y. Li, X. L. Cao, Y. Zhu et al., "Osa-miR398b boosts H2O2 production and rice blast disease-resistance via multiple superoxide dismutases," New Phytologist, 2019.

[54] F. J. Corpas, D. K. Gupta, and J. M. Palma, "Production sites of reactive oxygen species (ROS) in organelles from plant cells," in Reactive Oxygen Species and Oxidative Damage in Plants Under Stress, D. Gupta, J. Palma, and F. Corpas, Eds., pp. 1-22, Springer, Cham, Switzerland, 2015.

[55] K. Das and A. Roychoudhury, "Reactive oxygen species (ROS) and response of antioxidants as ROS-scavengers during environmental stress in plants," Frontiers in Environmental Science, vol. 2, p. 53, 2014.

[56] A. Saed-Moucheshi, H. Pakniyat, H. Pirasteh-Anosheh et al., "Chapter 20 - role of ROS as signaling molecules in plants," in Oxidative Damage to Plants, P. Ahmad, Ed., pp. 585-620, Academic Press, 2014.

[57] N. Navrot, N. Rouhier, E. Gelhaye, and J.-P. Jacquot, "Reactive oxygen species generation and antioxidant systems in plant mitochondria," Physiologia Plantarum, vol. 129, no. 1, pp. 185195, 2007.

[58] L. A. del Río, L. M. Sandalio, F. J. Corpas, J. M. Palma, and J. B. Barroso, "Reactive oxygen species and reactive nitrogen species in peroxisomes. Production, scavenging, and role in cell signaling," Plant Physiology, vol. 141, no. 2, pp. 330-335, 2006.

[59] P. I. Sharma, A. B. Jha, R. S. Dubey, and M. Pessarakli, "Reactive oxygen species, oxidative damage, and antioxidative defense mechanism in plants under stressful conditions," Journal of Botany, vol. 2012, Article ID 217037, 26 pages, 2012.

[60] B. C. H. Tripathy and R. Oelmüller, "Reactive oxygen species generation and signaling in plants," Plant Signaling and Behavior, vol. 7, no. 12, pp. 1621-1633, 2012.

[61] M. I. Dar, M. I. Naikoo, F. A. Khan et al., "An introduction to reactive oxygen species metabolism under changing climate in plants," in Reactive Oxygen Species and Antioxidant Systems in Plants: Role and Regulation under Abiotic Stress, M. Iqbal, R. Khan, and N. A. Khan, Eds., pp. 25-52, Singapore, 2017.

[62] T. Karuppanapandian, J.-C. Moon, C. Kim, K. Manoharan, and W. Kim, "Reactive oxygen species in plants: their generation, signal transduction, and scavenging mechanisms," Australian Journal of Crop Science, vol. 5, no. 6, pp. 709-725, 2011.

[63] J. M. Palms, F. J. Corpas, and L. A. Del Río, "Proteome of plant peroxisomes: new perspectives on the role of these organelles in cell biology," Proteomics, vol. 9, no. 9, pp. 2301-2312, 2009.

[64] R. Mittler, "Oxidative stress, antioxidants and stress tolerance," Trends in Plant Science, vol. 7, no. 9, pp. 405-410, 2002.

[65] X. Hu, A. Zhang, J. Zhang, and M. Jiang, "Abscisic acid is a key inducer of hydrogen peroxide production in leaves of maize plants exposed to water stress," Plant \& Cell Physiology (PCP), vol. 47, no. 11, pp. 1484-1495, 2006.

[66] A. Kärkönen and K. Kuchitsu, "Reactive oxygen species in cell wall metabolism and development in plants," Phytochemistry, vol. 112, no. 1, pp. 22-32, 2015.

[67] R. K. Kar, "ROS signaling: relevance with site of production and metabolism of ROS," 2015.

[68] X. Jing, P. Hou, Y. Lu et al., "Overexpression of copper/zinc superoxide dismutase from mangrove Kandelia candel in tobacco enhances salinity tolerance by the reduction of reactive oxygen species in chloroplast," Frontiers in Plant Science, vol. 6, p. 23, 2015.

[69] N. P. Negi, D. C. Shrivastava, V. Sharma, and N. B. Sarin, "Overexpression of CuZnSOD from Arachis hypogaea alleviates salinity and drought stress in tobacco," Plant Cell Reports, vol. 34, no. 7, pp. 1109-1126, 2015.

[70] A. Shafi, R. Chauhan, T. Gill et al., "Expression of SOD and APX genes positively regulates secondary cell wall biosynthesis and promotes plant growth and yield in Arabidopsis under salt stress," Plant Molecular Biology, vol. 87, no. 6, pp. 615-631, 2015.

[71] Q. Guan, Z. Wang, X. Wang, T. Takano, and S. Liu, "A peroxisomal APX from Puccinellia tenuiflora improves the abiotic stress tolerance of transgenic Arabidopsis thaliana through decreasing of $\mathrm{H}_{2} \mathrm{O}_{2}$ accumulation," Journal of Plant Physiology, vol. 175, pp. 183-191, 2015.

[72] J. R. Cunha, M. C. L. Neto, F. E. L. Carvalho et al., "Salinity and osmotic stress trigger different antioxidant responses related to cytosolic ascorbate peroxidase knockdown in rice roots," Environmental \& Experimental Botany, vol. 131, pp. 58-67, 2016.

[73] C. M. Chiang, H. L. Chien, L. F. O. Chen et al., "Overexpression of the genes coding ascorbate peroxidase from Brassica campestris enhances heat tolerance in transgenic Arabidopsis thaliana," Biologia Plantarum, vol. 59, no. 2, pp. 305-315, 2015.

[74] Y. Xu, P. Burgess, X. Zhang, and B. Huang, "Enhancing cytokinin synthesis by overexpressing ipt alleviated drought inhibition of root growth through activating ROS-scavenging systems in Agrostis stolonifera," Journal of Experimental Botany, vol. 67, no. 6, pp. 1979-1992, 2016.

[75] J. Xu, J. Yang, X. Duan, Y. Jiang, and P. Zhang, "Increased expression of native cytosolic $\mathrm{Cu} / \mathrm{Zn}$ superoxide dismutase and ascorbate peroxidase improves tolerance to oxidative and chilling stresses in cassava (Manihot esculenta Crantz)," BMC Plant Biology, vol. 14, no. 1, p. 208, 2014.

[76] Y. Hu, Q. Wu, S. A. Sprague et al., “Tomato expressing Arabidopsis glutaredoxin gene AtGRXS17 confers tolerance to chilling stress via modulating cold responsive components," Horticulture Research, vol. 2, p. 15051, 2015.

[77] R. Fryzova, M. Pohanka, P. Martinkova et al., "Oxidative stress and heavy metals in plants," in Reviews of Environmental Contamination and Toxicology, vol. 245 of Reviews of Environmental Contamination and Toxicology, pp. 129-156, Springer International Publishing, Cham, Switzerland, 2018. 
[78] M. G. Mostofa, Z. I. Seraj, and M. Fujita, "Exogenous sodium nitroprusside and glutathione alleviate copper toxicity by reducing copper uptake and oxidative damage in rice (Oryza sativa L.) seedlings," Protoplasma, vol. 251, no. 6, pp. 1373-1386, 2014.

[79] S. B. Agrawal, S. Singh, and M. Agrawal, "Chapter 3 ultraviolet$B$ induced changes in gene expression and antioxidants in plants," Advances in Botanical Research, vol. 52, pp. 47-86, 2009.

[80] W. Li, Z. Zhu, M. Chern et al., "A natural allele of a transcription factor in rice confers broad-spectrum blast resistance," Cell, vol. 170, no. 1, pp. 114-126, 2017.

[81] A. Wassim, B. R. Ichrak, and A. Saïda, "Putative role of proteins involved in detoxification of reactive oxygen species in the early response to gravitropic stimulation of poplar stems," Plant Signaling and Behavior, vol. 8, no. 1, pp. 1-6, 2013.

[82] M. Nath, D. Bhatt, R. Prasad et al., "Reactive oxygen species (ROS) metabolism and signaling in plant-mycorrhizal association under biotic and abiotic stress conditions," in Mycorrhiza - Eco-Physiology, Secondary Metabolites, Nanomaterials, A. Varma, R. Prasad, and N. Tuteja, Eds., pp. 223-232, Springer, Cham, Switzerland, 2017.

[83] M. M. Gaschler and B. R. Stockwell, "Lipid peroxidation in cell death," Biochemical and Biophysical Research Communications, vol. 482, no. 3, pp. 419-425, 2017.

[84] A. Catalá and M. Díaz, "Editorial: impact of lipid peroxidation on the physiology and pathophysiology of cell membranes," Frontiers in Physiology, vol. 7, p. 423, 2016.

[85] M. Repetto, J. Semprine, and A. Boveris, "Lipid peroxidation: chemical mechanism, biological implications and analytical determination," in Lipid Peroxidation, A. Catala, Ed., Angel Catala IntechOpen, 2012.

[86] E. E. Farmer and M. J. Mueller, "ROS-mediated lipid peroxidation and RES-activated signaling," Annual Review of Plant Biology, vol. 64, pp. 429-450, 2013.

[87] M. Reginato, C. Varela, A. M. Cenzano et al., "Role of polyphenols as antioxidants in native species from argentina under drought and salinization," in Reactive Oxygen Species and Oxidative Damage in Plants Under Stress, D. Gupta, J. Palma, and F. Corpas, Eds., pp. 247-267, Springer, Cham, Switzerland, 2015.

[88] S. Grimm, A. Höhn, and T. Grune, "Oxidative protein damage and the proteasome," Amino Acids, vol. 42, no. 1, pp. 23-38, 2012.

[89] A. Molassiotis, D. Job, V. Ziogas, and G. Tanou, "Citrus plants: a model system for unlocking the secrets of NO and ROSinspired priming against salinity and drought," Frontiers in Plant Science, vol. 7, p. 553, 2016.

[90] A. Caverzan, A. Casassola, and S. P. Brammer, "Antioxidant responses of wheat plants under stress," Genetics and Molecular Biology, vol. 39, no. 1, pp. 1-6, 2016.

[91] G. Cavallini, A. Sgarbossa, I. Parentini et al., "Dolichol: a component of the cellular antioxidant machinery," Lipids, vol. 51, no. 4, pp. 477-486, 2016.

[92] A. Delaunay-Moisan and C. Appenzeller-Herzog, "The antioxidant machinery of the endoplasmic reticulum: protection and signaling," Free Radical Biology \& Medicine, vol. 83, pp. 341-351, 2015.

[93] N. Tuteja, "Mechanisms of high salinity tolerance in plants," Methods in Enzymology, vol. 428, pp. 419-438, 2007.

[94] S. Pandey, D. Fartyal, A. Agarwal et al., "Abiotic stress tolerance in plants: myriad roles of ascorbate peroxidase," Frontiers in Plant Science, vol. 8, p. 581, 2017.
[95] Y. Kadota, K. Shirasu, and C. Zipfel, "Regulation of the NADPH oxidase RBOHD during plant immunity," Plant \& Cell Physiology (PCP), vol. 56, no. 8, pp. 1472-1480, 2015.

[96] W. B. Wang, Y. H. Kim, H. S. Lee et al., "Analysis of antioxidant enzyme activity during germination of alfalfa under salt and drought stresses," Plant Physiology \& Biochemistry, vol. 47, no. 7, pp. 570-577, 2009.

[97] F. Xu, L. Shi, W. Chen, S. Cao, X. Su, and Z. Yang, "Effect of blue light treatment on fruit quality, antioxidant enzymes and radical-scavenging activity in strawberry fruit," Scientia Horticulturae, vol. 175, pp. 181-186, 2014.

[98] S. Azarabadi, H. Abdollahi, M. Torabi, Z. Salehi, and J. Nasiri, "ROS generation, oxidative burst and dynamic expression profiles of ROS-scavenging enzymes of superoxide dismutase $(S O D)$, catalase $(C A T)$ and ascorbate peroxidase $(A P X)$ in response to Erwinia amylovora in pear (Pyrus communis L)," European Journal of Plant Pathology, vol. 147, no. 2, pp. 279-294, 2017.

[99] W. Wang, X. Zhang, F. Deng, R. Yuan, and F. Shen, "Genomewide characterization and expression analyses of superoxide dismutase (SOD) genes in Gossypium hirsutum," BMC Genomics, vol. 18, no. 1, p. 376, 2017.

[100] T. Chakradhar, S. Mahanty, R. A. Reddy et al., "Biotechnological perspective of reactive oxygen species (ROS)-mediated stress tolerance in plants," in Reactive Oxygen Species and Antioxidant Systems in Plants: Role and Regulation under Abiotic Stress, M. Khan and N. Khan, Eds., pp. 53-87, Springer, Singapore, 2017.

[101] S.-Y. Shin, M.-H. Kim, Y.-H. Kim, H.-M. Park, and H.-S. Yoon, "Co-expression of monodehydroascorbate reductase and dehydroascorbate reductase from Brassica rapa effectively confers tolerance to freezing-induced oxidative stress," Molecules and Cells, vol. 36, no. 4, pp. 304-315, 2013.

[102] P. Diaz-Vivancos, M. Faize, G. Barba-Espin et al., "Ectopic expression of cytosolic superoxide dismutase and ascorbate peroxidase leads to salt stress tolerance in transgenic plums," Plant Biotechnology Journal, vol. 11, no. 8, pp. 976-985, 2013.

[103] H. S. Marinho, C. Real, L. Cyrne, H. Soares, and F. Antunes, "Hydrogen peroxide sensing, signaling and regulation of transcription factors," Redox Biology, vol. 2, pp. 535-562, 2014.

[104] K.-J. Dietz, "Redox regulation of transcription factors in plant stress acclimation and development," Antioxidants \& Redox Signaling, vol. 21, no. 9, pp. 1356-1372, 2014.

[105] P. Woodrow, G. Pontecorvo, L. F. Ciarmiello, M. G. Annunziata, A. Fuggi, and P. Carillo, "Transcription factors and genes in abiotic stress," in Crop Stress and Its Management: Perspectives and Strategies, B. Venkateswarlu, A. Shanker, C. Shanker, and M. Maheswari, Eds., pp. 317-357, Springer, Netherlands, 2012.

[106] P.-F. Yao, C.-L. Li, X.-R. Zhao et al., "Overexpression of a tartary buckwheat gene, FtbHLH3, enhances drought/oxidative stress tolerance in transgenic Arabidopsis," Frontiers in Plant Science, vol. 8, p. 625, 2017.

[107] E. Yue, Z. Liu, C. Li, Y. Li, Q. Liu, and J.-H. Xu, "Overexpression of miR529a confers enhanced resistance to oxidative stress in rice (Oryza sativa L.)," Plant Cell Reports, vol. 36, no. 7, pp. 11711182, 2017.

[108] Z. H. Shah, H. M. Rehman, T. Akhtar et al., "Redox and ionic homeostasis regulations against oxidative, salinity and drought stress in wheat (a systems biology approach)," Frontiers in Genetics, vol. 8, p. 141, 2017.

[109] W.-H. Wang, E.-M. He, Y. Guo, Q.-X. Tong, and H.-L. Zheng, "Chloroplast calcium and ROS signaling networks potentially 
facilitate the primed state for stomatal closure under multiple stresses," Environmental and Experimental Botany, vol. 122, pp. 85-93, 2016.

[110] H. AbdElgawad, G. Zinta, M. M. Hegab, R. Pandey, H. Asard, and W. Abuelsoud, "High salinity induces different oxidative stress and antioxidant responses in maize seedlings organs," Frontiers in Plant Science, vol. 7, p. 580, 2016.

[111] M. N. Siddiqui, M. G. Mostofa, M. M. Akter et al., "Impact of salt-induced toxicity on growth and yield-potential of local wheat cultivars: oxidative stress and ion toxicity are among the major determinants of salt-tolerant capacity," Chemosphere, vol. 187, pp. 385-394, 2017.

[112] Y. Zhou, C. Liu, D. Tang et al., "The receptor-like cytoplasmic kinase STRK1 phosphorylates and activates CatC, thereby regulating $\mathrm{H} 2 \mathrm{O} 2$ homeostasis and improving salt tolerance in rice," The Plant Cell, vol. 30, no. 5, pp. 1100-1118, 2018.

[113] A. L. Furlan, E. Bianucci, and S. Castro, "Signaling role of ROS in modulating drought stress tolerance," in Drought Stress Tolerance in Plants, Vol 1: Physiology and Biochemistry, L. S. Tran, Ed., Springer, Cham, Switzerland, 2016.

[114] H. Xiong, J. Yu, J. Miao et al., "Natural variation in OsLG3 increases drought tolerance in rice by inducing ROS scavenging," Plant Physiology, vol. 178, no. 1, pp. 451-467, 2018.

[115] M. Yin, Y. Wang, L. Zhang et al., "The Arabidopsis Cys2/His2 zinc finger transcription factor ZAT18 is a positive regulator of plant tolerance to drought stress," Journal of Experimental Botany, vol. 68, no. 11, pp. 2991-3005, 2017.

[116] F.-Z. Wang, Q.-B. Wang, S.-Y. Kwon, S.-S. Kwak, and W.A. $\mathrm{Su}$, "Enhanced drought tolerance of transgenic rice plants expressing a pea manganese superoxide dismutase," Journal of Plant Physiology, vol. 162, no. 4, pp. 465-472, 2005.

[117] Y.-Y. Lu, X.-P. Deng, and S.-S. Kwak, "Over expression of CuZn superoxide dismutase (CuZn SOD) and ascorbate peroxidase (APX) in transgenic sweet potato enhances tolerance and recovery from drought stress," African Journal of Biotechnology, vol. 9, no. 49, pp. 8378-8391, 2010.

[118] S. Stankovic, P. Kalaba, and A. R. Stankovic, "Biota as toxic metal indicators," Environmental Chemistry Letters, vol. 12, no. 1, pp. 63-84, 2014.

[119] R. Juknys, G. Vitkauskaitè, M. Račaite, and J. Venclovienè, “The impacts of heavy metals on oxidative stress and growth of spring barley," Open Life Sciences, vol. 7, no. 2, pp. 299-306, 2012.

[120] M. Shahid, B. Pourrut, C. Dumat, M. Nadeem, M. Aslam, and E. Pinelli, "Heavy-metal-induced reactive oxygen species: phytotoxicity and physicochemical changes in plants," Reviews of Environmental Contamination and Toxicology, vol. 232, pp. 144, 2014.

[121] M. Valko, H. Morris, and M. T. D. Cronin, "Metals, toxicity and oxidative stress," Current Medicinal Chemistry, vol. 12, no. 10, pp. 1161-1208, 2005.

[122] M. Adrees, S. Ali, M. Iqbal et al., "Mannitol alleviates chromium toxicity in wheat plants in relation to growth, yield, stimulation of anti-oxidative enzymes, oxidative stress and $\mathrm{Cr}$ uptake in sand and soil media," Ecotoxicology and Environmental Safety, vol. 122, pp. 1-8, 2015.

[123] S. S. Sharma and K. J. Dietz, "The relationship between metal toxicity and cellular redox imbalance," Trends in Plant Science, vol. 14, no. 1, pp. 43-50, 2009.

[124] C. O. Ogunkunle, M. Varun, I. G. Ogundele, K. S. Olorunmaiye, and M. S. Paul, "Citrus epicarp-derived biochar reduced Cd uptake and ameliorates oxidative stress in young Abelmoschus esculentus (L.) Moench (okra) under low Cd stress," Bulletin of Environmental Contamination and Toxicology, vol. 100, no. 6, pp. 827-833, 2018.

[125] A. Schützendübel and A. Polle, "Plant responses to abiotic stresses: heavy metal-induced oxidative stress and protection by mycorrhization," Journal of Experimental Botany, vol. 53, no. 372, pp. 1351-1365, 2002.

[126] C. Barta, T. Kálai, K. Hideg, I. Vass, and É. Hideg, “Differences in the ROS-generating efficacy of various ultraviolet wavelengths in detached spinach leaves," Functional Plant Biology, vol. 31, no. 1, pp. 23-28, 2004.

[127] E. Abdel Haliem, H. Abdullah, and A. A. Al-Huqail, "Oxidative damage and mutagenic potency of fast neutron and uv-b radiation in pollen mother cells and seed yield of Vicia faba L," BioMed Research International, vol. 2013, Article ID 824656, 12 pages, 2013.

[128] C. D. Leasure, H. Tong, G. Yuen, X. Hou, X. Sun, and Z.-H. He, "Root UV-B sensitive2 acts with root UV-B sensitivel in a root ultraviolet B-sensing pathway," Plant Physiology, vol. 150, no. 4, pp. 1902-1915, 2009.

[129] X. Luo, N. Xu, J. Huang et al., "A lectin receptor-like kinase mediates pattern-triggered salicylic acid signaling," Plant Physiology, vol. 174, no. 4, pp. 2501-2514, 2017.

[130] D. Couto and C. Zipfel, "Regulation of pattern recognition receptor signalling in plants," Nature Reviews Immunology, vol. 16, no. 9, pp. 537-552, 2016.

[131] M. A. Torres and J. L. Dangl, "Functions of the respiratory burst oxidase in biotic interactions, abiotic stress and development," Current Opinion in Plant Biology, vol. 8, no. 4, pp. 397-403, 2005.

[132] M. Sagi and R. Fluhr, "Superoxide production by plant homologues of the gp91phox NADPH oxidase. Modulation of activity by calcium and by tobacco mosaic virus infection," Plant Physiology, vol. 126, no. 3, pp. 1281-1290, 2001.

[133] Y. Sang and A. P. Macho, "Analysis of PAMP-triggered ROS burst in plant immunity", in Plant Pattern Recognition Receptors: Methods and Protocols, L. Shan and P. He, Eds., pp. 143-153, Springer, New York, NY, USA, 2017.

[134] Y. Liu and C. He, "Regulation of plant reactive oxygen species (ROS) in stress responses: learning from AtRBOHD," Plant Cell Reports, vol. 35, no. 5, pp. 995-1007, 2016.

[135] Q. Li, G. Ai, D. Shen et al., "A phytophthora capsici effector targets ACD11 binding partners that regulate ROS-mediated defense response in arabidopsis," Molecular Plant, vol. 12, no. 4, pp. 565-581, 2019.

[136] D. Arnaud, S. Lee, Y. Takebayashi et al., "Cytokinin-mediated regulation of reactive oxygen species homeostasis modulates stomatal immunity in arabidopsis," The Plant Cell, vol. 29, no. 3, pp. 543-559, 2017.

[137] E. Kámán-Tóth, T. Dankó, G. Gullner, Z. Bozsó, L. Palkovics, and M. Pogány, "Contribution of cell wall peroxidase- and NADPH oxidase-derived reactive oxygen species to Alternaria brassicicola -induced oxidative burst in Arabidopsis," Molecular Plant Pathology, vol. 20, no. 4, pp. 485-499, 2019.

[138] S. Gilroy, N. Suzuki, G. Miller et al., "A tidal wave of signals: calcium and ROS at the forefront of rapid systemic signaling," Trends in Plant Science, vol. 19, no. 10, pp. 623-630, 2014.

[139] Y. Bai, C. Kissoudis, Z. Yan, R. G. F. Visser, and G. van der Linden, "Plant behaviour under combined stress: tomato responses to combined salinity and pathogen stress," The Plant Journal, vol. 93, no. 4, pp. 781-793, 2018. 


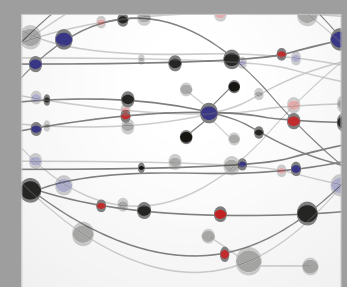

The Scientific World Journal
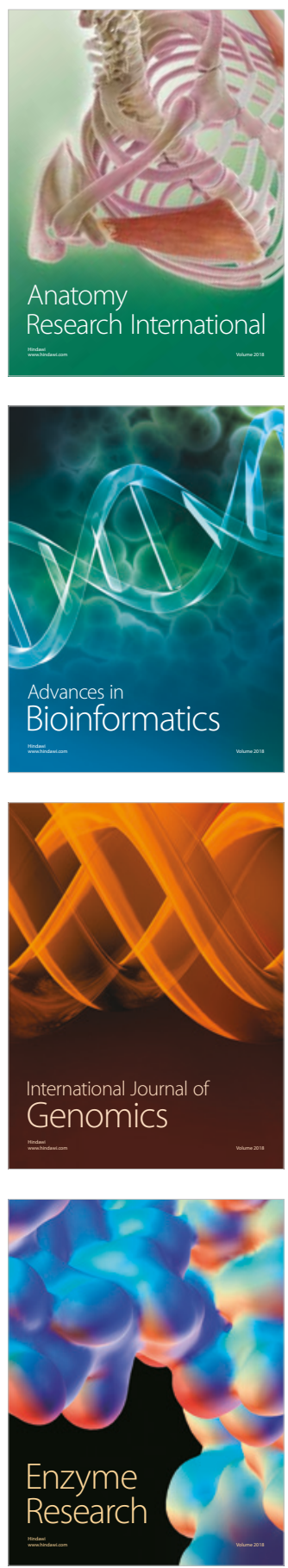
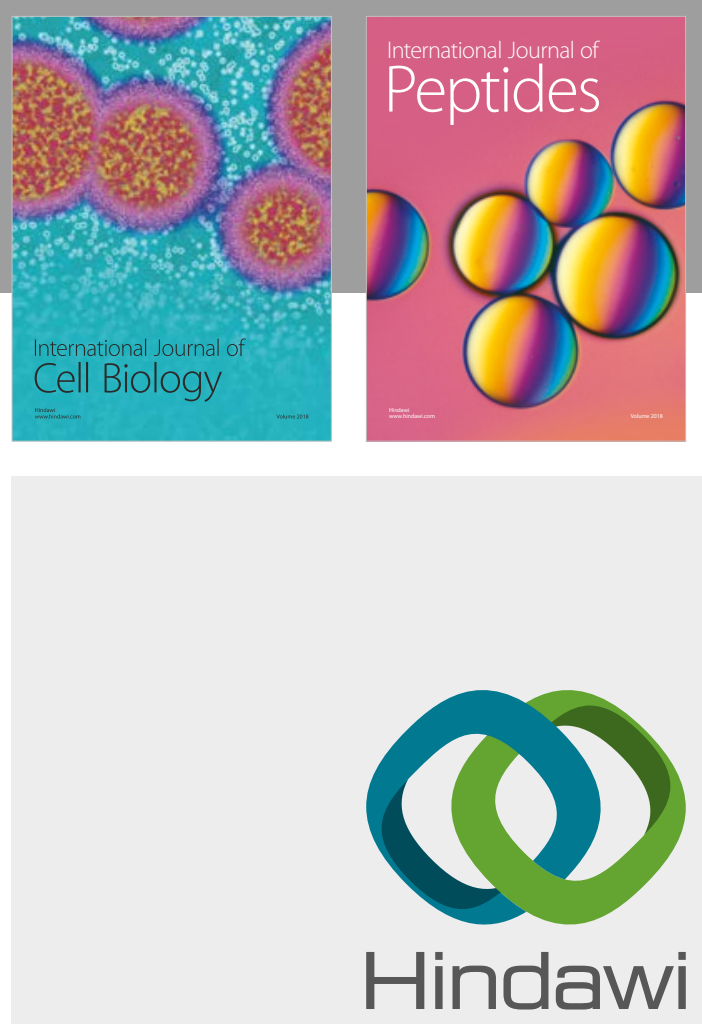

Submit your manuscripts at

www.hindawi.com
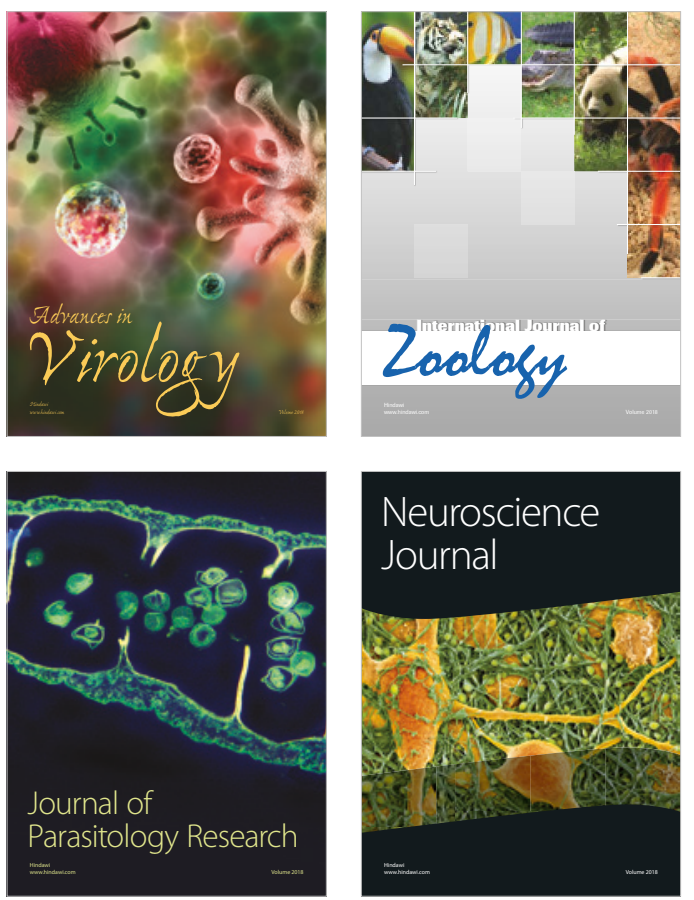
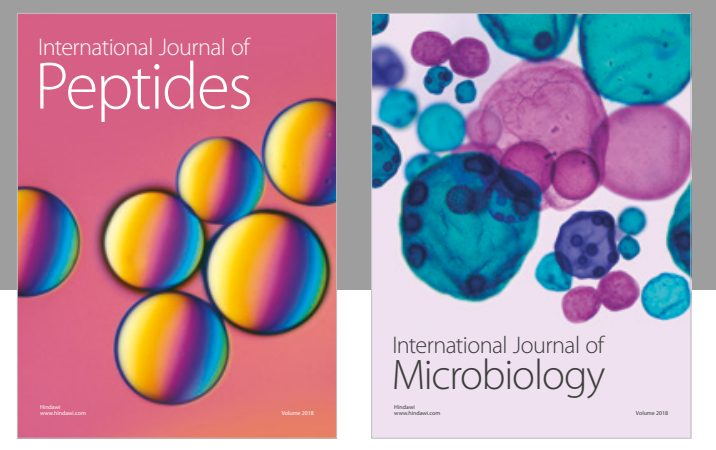

nternational Journal of Microbiology
Journal of
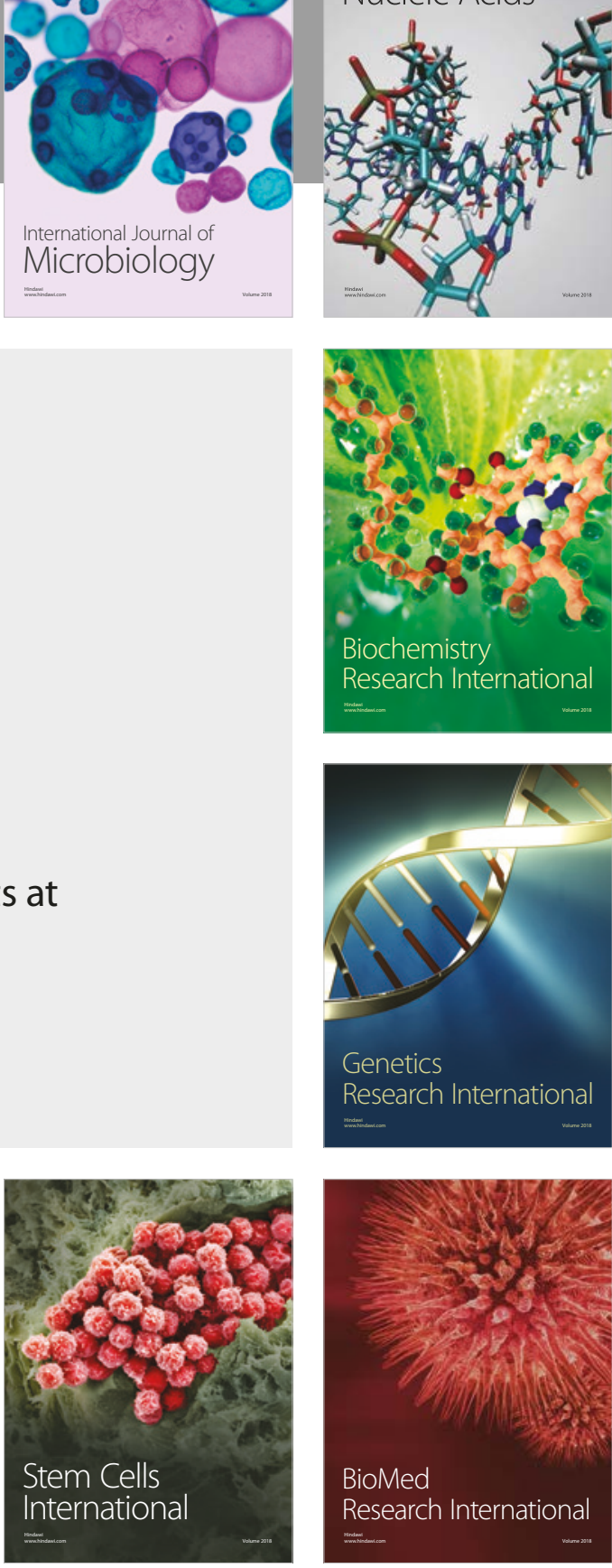
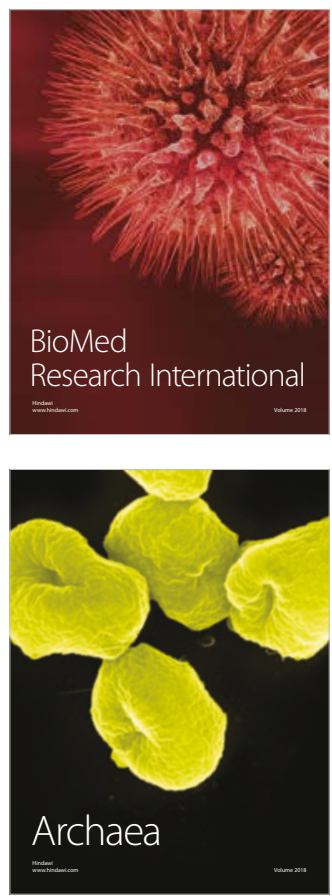